Article

\title{
Optimized Design and Discussion on Middle and Large CANDLE Reactors
}

\author{
Mingyu Yan *, Yong Zhang and Xiaoming Chai \\ Nuclear Power Institute of China, Chengdu 518028, China; E-Mails: zhylq@sohu.com (Y.Z.); \\ chaixiaoming@npic.ac.cn (X.C.) \\ * Author to whom correspondence should be addressed; E-Mail: megatron-prime@hotmail.com; \\ Tel.: +86-135-4068-8682; Fax: +86-28-8590-8191.
}

Received: 2 June 2012; in revised form: 14 July 2012 / Accepted: 18 July 2012 /

Published: 21 August 2012

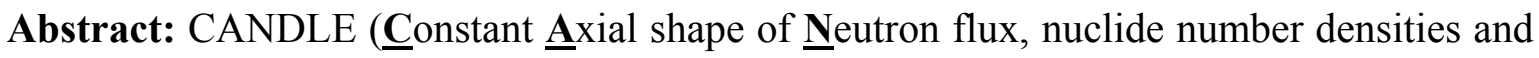

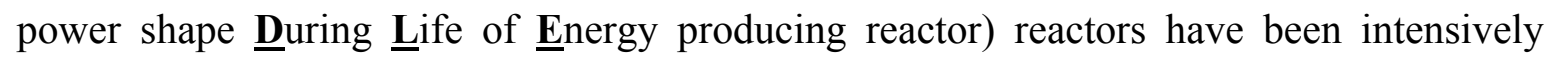
researched in the last decades [1-6]. Research shows that this kind of reactor is highly economical, safe and efficiently saves resources, thus extending large scale fission nuclear energy utilization for thousands of years, benefitting the whole of society. For many developing countries with a large population and high energy demands, such as China and India, middle (1000 MWth) and large (2000 MWth) CANDLE fast reactors are obviously more suitable than small reactors [2]. In this paper, the middle and large CANDLE reactors are investigated with $\mathrm{U}-\mathrm{Pu}$ and combined $\mathrm{ThU}-\mathrm{UPu}$ fuel cycles, aiming to utilize the abundant thorium resources and optimize the radial power distribution. To achieve these design purposes, the present designs were utilized, simply dividing the core into two fuel regions in the radial direction. The less active fuel, such as thorium or natural uranium, was loaded in the inner core region and the fuel with low-level enrichment, e.g. $2.0 \%$ enriched uranium, was loaded in the outer core region. By this simple core configuration and fuel setting, rather than using a complicated method, we can obtain the desired middle and large CANDLE fast cores with reasonable core geometry and thermal hydraulic parameters that perform safely and economically; as is to be expected from CANDLE. To assist in understanding the CANDLE reactor's attributes, analysis and discussion of the calculation results achieved are provided.
\end{abstract}

Keywords: CANDLE reactor; Traveling-Wave reactor; sustainability 


\section{Introduction}

The development of human society and the growth of the global population cause huge energy demands and various environmental problems. The reality of this and current technical capabilities leave human society with only one choice — nuclear fission energy — as fusion energy is not yet ready for large scale commercial utilization. In the past half century, hundreds of thermal spectrum reactors consumed too much of our precious uranium resources and many reactors of this kind will still be built in the future. How to solve problems such as the efficiency of utilizing the nuclear resources and the recycling of the spent fuel from light water reactors, have become the key points for the sustainable development of fission energy utilization.

Fortunately, the CANDLE burnup concept [1] gives us the opportunity to satisfy all these needs just by one process, namely the burnup of the CANDLE reactors. Moreover, intensive and comprehensive research over the past decade already demonstrates that a CANDLE reactor maintains a lot of attractive merits [1-6], summarized in the following.

\subsection{Super Fuel Utilization Capability}

The CANDLE reactor has a hard neutron spectrum and the burnup divides the core into a fresh fuel region, burning region and spent fuel region automatically. These three physical regions are spatially separated. The spent fuel region and fresh fuel region only absorb the neutrons that have already escaped from the burning region. As a result, the negative effect on the neutron economy by poisonous absorption of spent fuel can be minimized and the neutrons generated in the burning region can be utilized efficiently, resulting in high conversion and burnup ratios. Refueling is no longer needed throughout the life of the core if the time dependent integrity of key parts, such as the cladding, is assured. Meanwhile, the conversion speed of the fertile nuclides in the fresh fuel region is also limited, contributing to a stable and slow burnup process, which aids the ease of control and long core life.

If a light water reactor (LWR) produced energy of X Joules, a CANDLE reactor can produce about $50 \mathrm{X}$ Joules from the depleted uranium left at the enrichment facility for the LWR fuel. If LWRs produced energy for 20 years, we can produce energy for 1000 years by using the CANDLE reactor with the depleted uranium. There is no need to mine uranium ore, nor is a reprocessing facility needed. The burnup of spent fuel escalates 10 times by use of CANDLE reactors. Therefore, the amount of spent fuel relative to the energy produced is also reduced to one-tenth.

\subsection{Highly Stable Operation throughout the Life of the Core}

Based on the inherent balance between the generation and vanishing of the neutrons, the core power and reactivity should not change throughout the life of the core, so long as there is no outside disturbance. This means the core would automatically run at just critical point, without excessive reactivity.

\subsection{No Need for the Burnup Control Rod Mechanism}

Consequently, there is no neutron loss and neutron distribution disturbance induced by the rod mechanism and there is no possibility of an unexpected burnup control rod ejection accident. In this 
regard, the core configuration and operation are highly simplified. The adjustment of the core power will be accomplished by the shifting of the primary coolant pumps.

\subsection{Radial Power Distribution Can Be Greatly Optimized}

Optimized radial power distribution can be automatically maintained throughout the life of the core, enhancing the cost and safety.

\subsection{Extremely Long Core Life Can Be Easily Realized}

Taking advantage of the CANDLE burnup, the core life can be easily extended by increasing the core height. Furthermore, due to the lower burn velocity, which is usually a few centimeters per year, the super long core life design can be achieved by small load inventory. Theoretically, there is no time limit by removing the spent fuel region and adding a fresh fuel region, while keeping a constant core height.

\subsection{No Need for Refueling during the Core Life, if Material Integrity Could Be Assured}

A CANDLE reactor has, therefore, the potential to be produced for commercial export and can also be shipped back to the producer for decommissioning. The users do not need to make contact with the nuclear materials, nor indeed is contact possible. This fact is of utmost importance for use in the developing countries and for the producers.

\subsection{Low Infinite Neutron Multiplication Factor of Fresh Fuel}

CANDLE reactor utilizes natural or very low-level enriched fuel and there is no risk of reaching unexpected critical levels of fresh fuel. This aids in fresh fuel storage and transportation.

\subsection{Advanced Inherent Safety Features}

The CANDLE reactor is accompanied with a liquid metal cooling system. Many design details can contribute to the safety, such as the fuel pin bond design and the integrated pool type design, etc. The safety benefits would also be enhanced by the advanced passive safety systems, which comply with the "defense in depth" rule.

Besides these points, the core of a CANDLE reactor has special safety features, distinguishing it from other fission reactors. The first one, as mentioned above, is that it always runs automatically at the perfect critical point. The core would instantly adjust its operation to a corresponding safe state, according to the reactivity insertion, and does not need any help from the systems. Secondly, the enrichment of the fissile nuclides is extremely low in the fresh fuel. The vast majority of the fissile nuclides only come from the conversion of fertile nuclides, which takes a lot of time. This leads to a valuable delay to any hazardous reactivity that might change the physical composition of the core, leaving enough time to take necessary measures.

According to previous safety research [5], a CANDLE reactor can independently handle very severe accidents and has the capability to overcome the beyond design basis accidents (BDBA), such as 
the ULOF + ULOHS with the help of passive safety systems and the atmosphere heat sink. There is no need for operator intervention in the whole process.

\subsection{Attractive Economy}

Different types of CANDLE reactors cover a very wide power range and are suitable for different energy demands, providing high quality working liquids $(>773 \mathrm{~K})$ under atmospheric pressure, enabling a thermal efficiency higher than $40 \%$.

\subsection{Efficient Utilization of Thorium Fuel}

Thorium fuel can be loaded in the inner region of a CANDLE core, leveling the core radial power distribution, improving the economy and safety, and reducing the core height; more importantly, improving the sustainable development of the entire nuclear power industry.

The 1000 MWth and 2000 MWth CANDLE reactors that offer these attributes are obviously attractive. The core layout sketches are shown in Figures 1 and 9, respectively. One of the goals of this paper is to try to go a step further toward engineering application by optimizing the radial neutron flux distribution. For this purpose, we divided the core into two concentric fuel regions in the radial direction. The thorium, depleted or natural uranium is utilized in the inner region and low-level enriched uranium is used in the outer region. At the same time, the "smear density" of the inner region is reduced for adaptation to high burnup and the empty space provides the channels for shut down control rod assemblies and experiment/detection equipment channels, and so on. The question of exactly how much empty space is needed is not discussed here and can be easily adjusted by the method we provide in this paper. The low-level enriched uranium in the outer region compensates for the reactivity loss introduced by the "inert" inner region and keeps the core at the correct size. The slightly enriched fuel in the outer region is a distinguishing point from the previous primary design [2], which ignored the engineering requirements. However, it would not overthrow the extremely efficient fuel utilization characteristic of the CANDLE, compared with the inherent high conversion and burnup ratio in the once-through cycle.

Figure 1. Sketch of the 1000 MWth CANDLE core configuration.
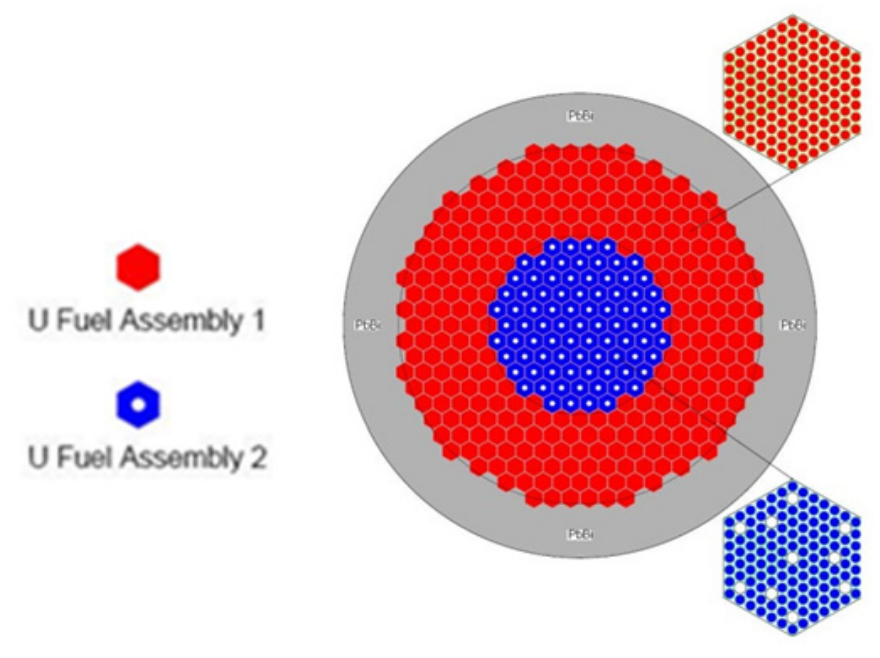
By this method, a flat radial neutron flux distribution is produced, with an even integral radiation dose for most of the fuel assemblies and optimized thermal hydraulic conditions, which is important for a high power level reactor. In the following sections, we present the results and discussion in detail.

\section{Results and Discussion}

\subsection{Calculation Conditions}

For more precise designs, we developed an original CANDLE code system, adopting the 3D MCMG (based on Monte Carlo theory) transport method [7] coupled with the thermal-hydraulic and neutronic interaction. This code system calculates the number densities of the nuclides, the neutron flux distributions, the Keff and the distributions of the thermal-hydraulic parameters in 3D cylindrical coordinates. The comparison between our previous 2D diffusion code and 3D transport code shows good consistency. Both the 2D and 3D calculations are applied to 21 neutron energy groups.

The $2 \mathrm{D}$ diffusion code uses the simple R-Z coordinates for the cylindrical core with few energy groups. The geometry meshes of this code are limited to the shapes of concentric cylinders. The calculation precision can be highly preserved if the core is homogeneously composed. The problem of proof of precision is encountered in a core design with engineering heterogeneity. Therefore, the 2D diffusion code is good enough for CANDLE burnup theory research and we developed the $3 \mathrm{D}$ diffusion and transport codes for the engineering core design, such as the MCMG code in the following. The 2D diffusion code has been estimated by IAEA, through the program "RBEC-M Depletion Benchmark Calculation, RCM of CRP i25001, IAEA". The precision and reliability have been strictly checked.

The MCMG code is a $3 \mathrm{D}$ multigroup $\mathrm{P}_{3}$ Monte Carlo neutron transport code. It can treat complicated geometry like the hexagonal meshes of actual assemblies and has excellent variance reduction techniques. The number of energy groups in the MCMG code can be varied from a few groups to a multigroup (more than 100 groups), according to individual needs. Either macroscopic or microscopic cross sections can be used and its format is designed in accordance with the ANISN format. The MCMG code has been parallelized in the Parallel Virtual Machine (PVM) and the Message Passing Interface (MPI). The speedup increases linearly with the number of processors. Numerical tests show that the MCMG code can calculate the neutron transport problems accurately.

The current thermal-hydraulic calculation of the core adopted the Additional Heat Source method, in which the heat transfer between a fuel pin and the surrounding coolant is treated as an "additional heat source" in the calculation of the fuel pin temperature distribution. By this method, the temperature field and flow field in the core region are implicitly integrated and solved through iterations. The thermal-hydraulic calculation considers the axial and radial heat conductions in the fuel cell, the heat conduction between the fuel cell and the cladding through the liquid metal bond, and the heat transfer between the cladding and coolant. The newly introduced fuel cell axial heat conduction calculation contributes to more precise results for the thermal estimation and the feedback for microscopic cross sections, since the fuel cells have large diameters and sharp axial temperature gradients in a CANDLE core. 
The SRAC2006 code [8] was adopted to generate the microscopic cross section library, which has 96 sets used for interpolation, according to the change of temperature field and burnup depth. This library is based on the major neutron data library SRACLIB-JDL33. The U4cm466fp burnup chain and the th2cm6fp50bp16F burnup chain are applied to the $1000 \mathrm{MW}$ th case and the $2000 \mathrm{MWth}$ case, respectively.

\subsection{The Design and Results of the 1000 MWth CANDLE Reactor}

The inner region is composed of type 2 fuel assemblies, while the outer region is filled with type 1 fuel assemblies, surrounded by a $50 \mathrm{~cm}$ thick LBE reflector. Each assembly of the outer region is made up of the triangularly assembled cylindrical fuel pins with a U235 enrichment of $2.7 \%$. Each assembly in the inner region has an empty space ratio of $7.87 \%$, which can be utilized for the channels of the shutdown control rod assemblies and the experimental/detective equipment. The empty channels are uniformly scattered in every inner core assembly for easier simulation and will be gathered into specific units in each case. N15 enriched nitride natural uranium is the fuel used in the inner region. The main design parameters are shown in Table 1.

Table 1. The 1000 MWth CANDLE core design parameters.

\begin{tabular}{cc}
\hline Main Design Parameters & Values/Specifications \\
\hline Thermal Power/MWth & 1000 \\
Core Height/cm & 230 \\
Core Radius/cm & 165 \\
Radius of Inner Core/cm & 82.5 \\
Thickness of Reflector/cm & 50 \\
Fuel Cell Radius $/ \mathrm{mm}$ & 6 \\
Thickness of Cladding/mm & 0.5 \\
Distance between fuel pins/mm & 0.8 \\
Fuel Material of Inner Core & Natural UN \\
Fuel Material of Outer Core & Enrichment $2.7 \% \mathrm{UN}$ \\
Cladding Material & $\mathrm{HT}-9$ \\
Coolant Material & LBE $(44.5 \%-55.5 \%)$ \\
Reflector Material & LBE $(44.5 \%-55.5 \%)$ \\
Core Inlet Temp $/ \mathrm{K}$ & 600 \\
Core Outlet Temp Peak/K & 800 \\
\hline
\end{tabular}

The 1000 MWth power level is the preferred choice for places with middle energy demands, such as the western cities of China which are spread over a large area and lack water. For an easier engineering approach, we adopted the conventional cylindrical fuel pins with a relatively large pellet diameter, instead of the tube-in-shell type with hexagonal surface adopted in the previous design of the small long life CANDLE reactor [2]. As a result, the fuel volume ratio of the present design cannot be increased as much as in the previous one. The size of the core is increased and the fuel in the outer region is mildly enriched. The optimized radial power distribution enables a high average enthalpy of the outlet coolant with a large safety margin. The N15 enriched uranium is used as fresh fuel. This application takes pressure off the need for mining and processing, while greatly reducing the 
generation of C14 from N14 through the (n, p) reaction. Further, the extremely high melting point of the nitride fuel improves the core safety. F/M stainless steel HT-9 is chosen for the cladding material due to its good ability to maintain integrity in the LBE coolant and the long life expectancy. The coolant inlet temperature and the maximum outlet temperature are set at $600 \mathrm{~K}$ and $800 \mathrm{~K}$, respectively. This temperature range is suitable for the integrity of core materials while allowing economically efficient energy production. Also, large margins are permitted within the temperature limits and the safety of the core can be assured in case of accidents.

The key results are shown in Table 2 .

Table 2. The key results of the 1000 MWth CANDLE reactor design.

\begin{tabular}{cc}
\hline Key Results & Values \\
\hline Keff & 1.0018 \\
Burnup Velocity/cm/year & 1.59 \\
Max Burnup Depth/\% & 57.0 \\
Fuel Cell Temp Peak/K & 883.4 \\
Cladding Temp Peak/K & 801.2 \\
Maximum Coolant Velocity $/ \mathrm{m} / \mathrm{s}$ & 2.2 \\
\hline
\end{tabular}

With the present design, the Keff can be very close to unity and the little discrepancy of $1.8 \mathrm{e}-3$ would be easily corrected with the reactivity feedback in actual performance. The burnup velocity of $1.59 \mathrm{~cm} /$ year gives a core life of more than 50 years without reactivity fluctuation, according to the core height value. If we ignore the material problems here, this core can be regarded as a nuclear battery, which generates the energy very stably without burnup control and needs no refueling. The high burnup ratio is a merit and a challenge at the same time. The core can burn almost half of the loaded fertile materials in one life, greatly improving the utilization capability of the nuclear resources. On the other hand, no known material can survive this high burnup and last until the end of the core life. Ensuring the integrity of the cladding material would not pose any risk in the long run, and new materials and measures are under investigation. The temperature peaks of the fuel pellet and the cladding are quite low compared with their corresponding temperature limits.

Figures 2 and 3 present the equilibrium number density distributions of nuclide U238 and Pu239, respectively. The core is divided into 10 equidistant circles in the radial direction. Every line in the two figures presents the number density information of every circle. We put the 10 circles into two groups, representing the inner core region and outer core region, respectively, to show the effect of the design. The curves located in the inner region and outer region are marked by pairs of arrows. The number density of the nuclides in the inner region is volume weighted, since there are empty channels in the assemblies. These two figures reveal that the fuel conversion and burnup ratios of this core are rather high. The nuclide number density distributions of the different radial rings in the inner core almost overlap each other. This reflects that the burnup is uniform in the different radial circles, which would generate a flat neutron flux distribution. The core utilizes the fertile nuclides very efficiently, while on the other hand, posing a challenge to the core materials. 
Figure 2. The equilibrium nuclide number density distribution of U238.

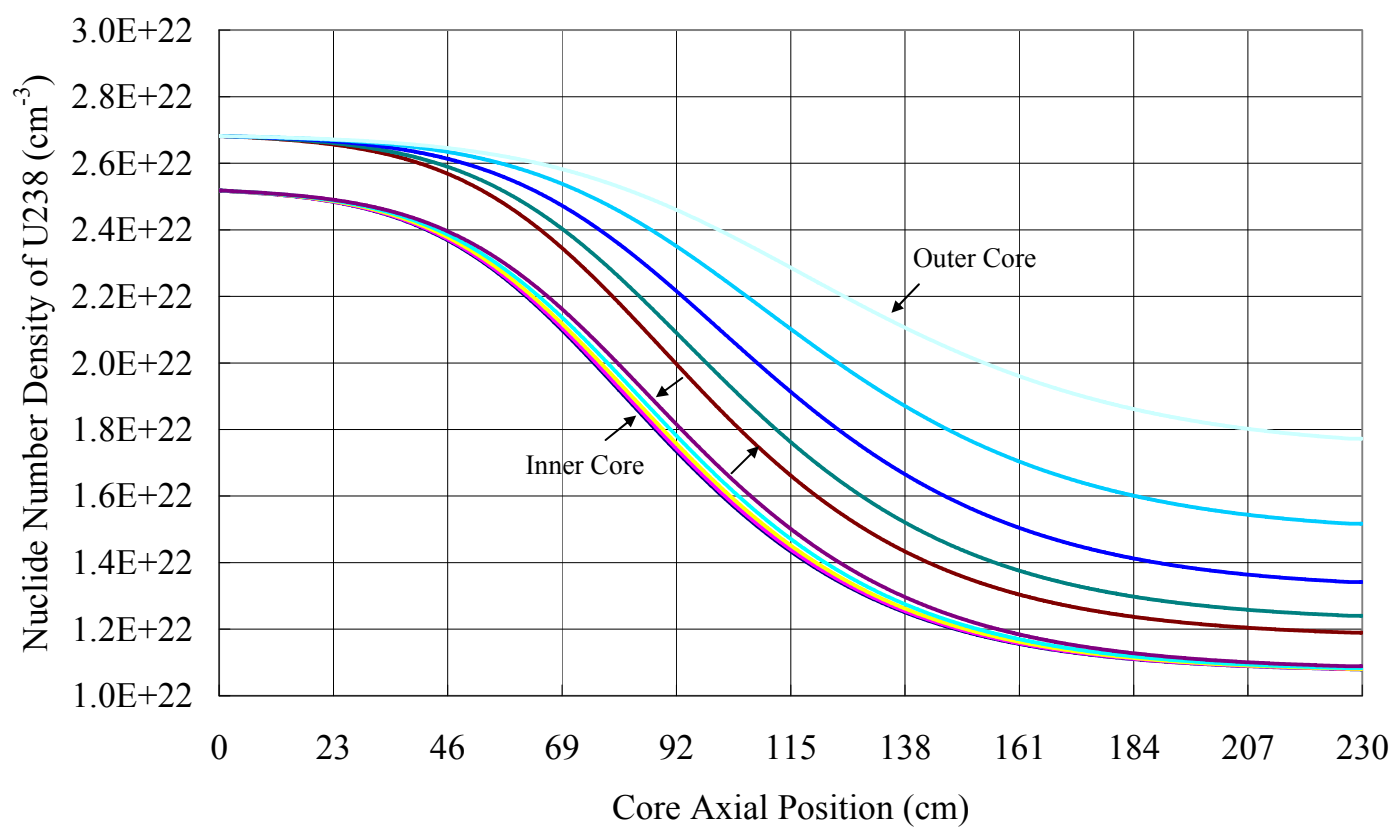

Figure 3. The equilibrium nuclide number density distribution of Pu239.

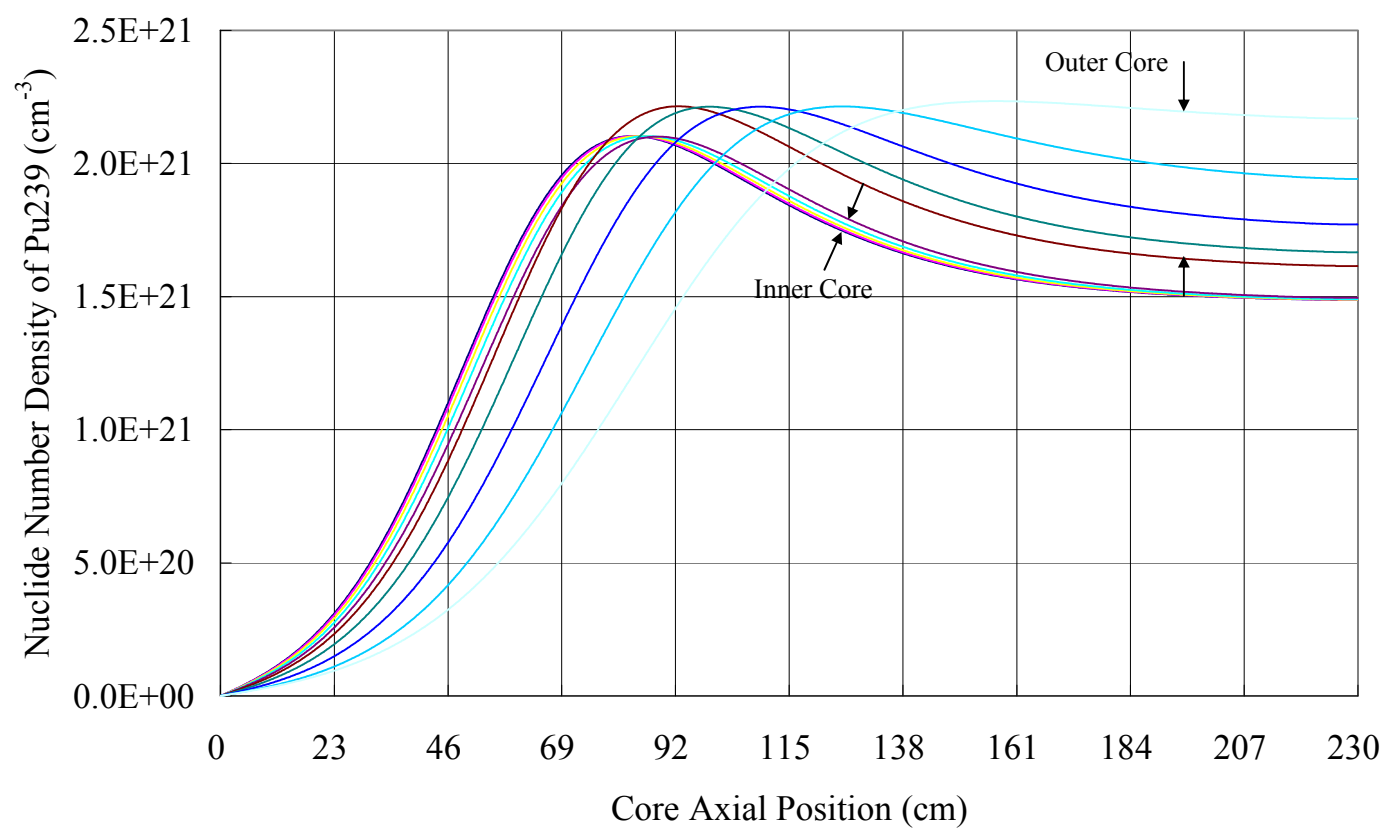

Figure 4 shows the infinite neutron multiplication factor distribution (Kinf). It is mainly dominated by the number density distribution of the Pu239 transmuted from U238 and it clearly divides the core axis into the fresh fuel region, the burning region and the spent fuel region, according to the factor values. On the left side of Figure 4 (fresh fuel region), the factor of the outer region is higher than that of the inner region, because the outer region is enriched to a low level. 
Figure 4. The infinite neutron multiplication factor distribution.

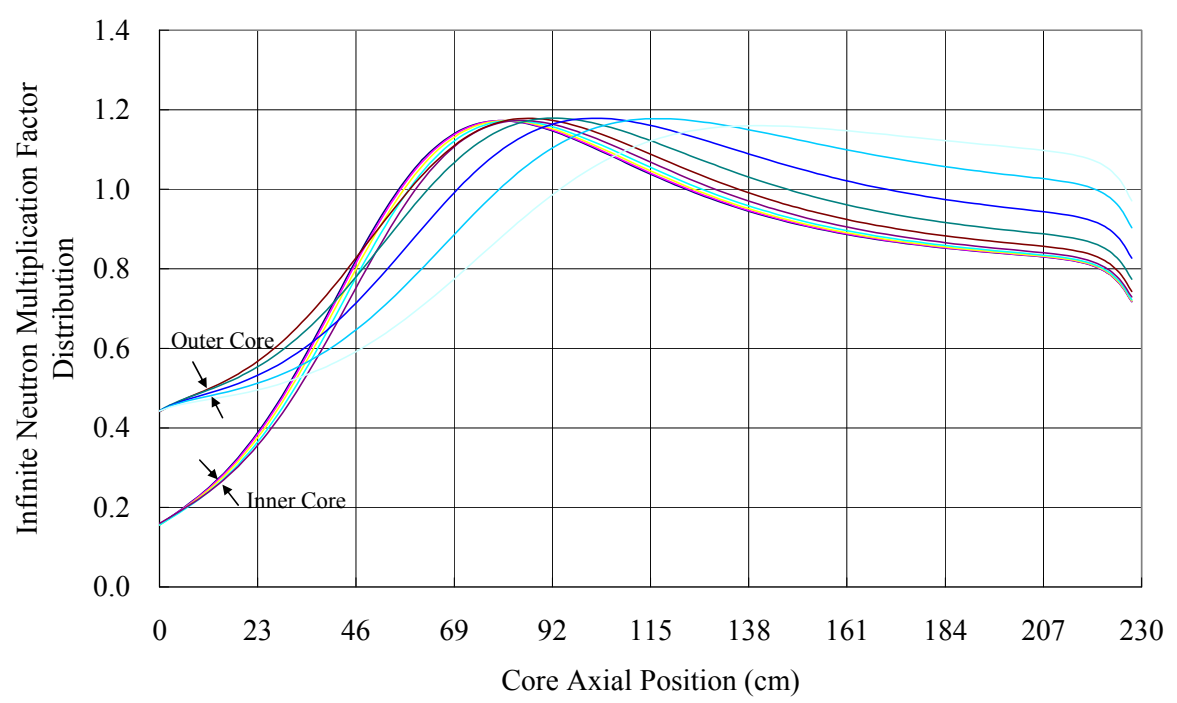

Figures 5 and 6 show that the radial neutron flux distribution and radial thermal power distribution were successfully flattened. The inner region is covered by a very flat distribution, as shown in the 3D figures of Figure 7. In the axial direction of the core, on each axial layer of the burning region, $25 \%$ of the area is covered by the same flux level. Also, more than $72 \%$ of the area is covered by the neutron flux, i.e. between $1.65 \mathrm{e} 15 \mathrm{~cm}^{-2} \mathrm{~s}^{-1}$ to $1.0 \mathrm{e} 15 \mathrm{~cm}^{-2} \mathrm{~s}^{-1}$ at the axial flux peak. According to Figure 5, the burning region materials that are exposed to the highest flux radiation would take about 18.8 years to reach the damage neutron fluence limit, which is about $250 \mathrm{dpa}\left(5.0 \mathrm{e} 23 \mathrm{~cm}^{-2}\right)$ [9], from new. The counted neutron flux has an energy level higher than $0.1 \mathrm{MeV}$, which is about $50 \%$ of the summation for the present case. In other words, after every performance period of 18.8 years, proper measures such as the "recladding procedure" [10] should be carried out. In such a procedure, all of the fuel pins would be entirely recladded for the longest performance periods. Meanwhile, the spent fuel would be removed and fresh fuel would be added at the two axial core ends, respectively. After this procedure, the state of the core will be rejuvenated and the new operation period will repeat the burnup process of the previous 18.8 years.

Figure 5. The neutron flux distribution.

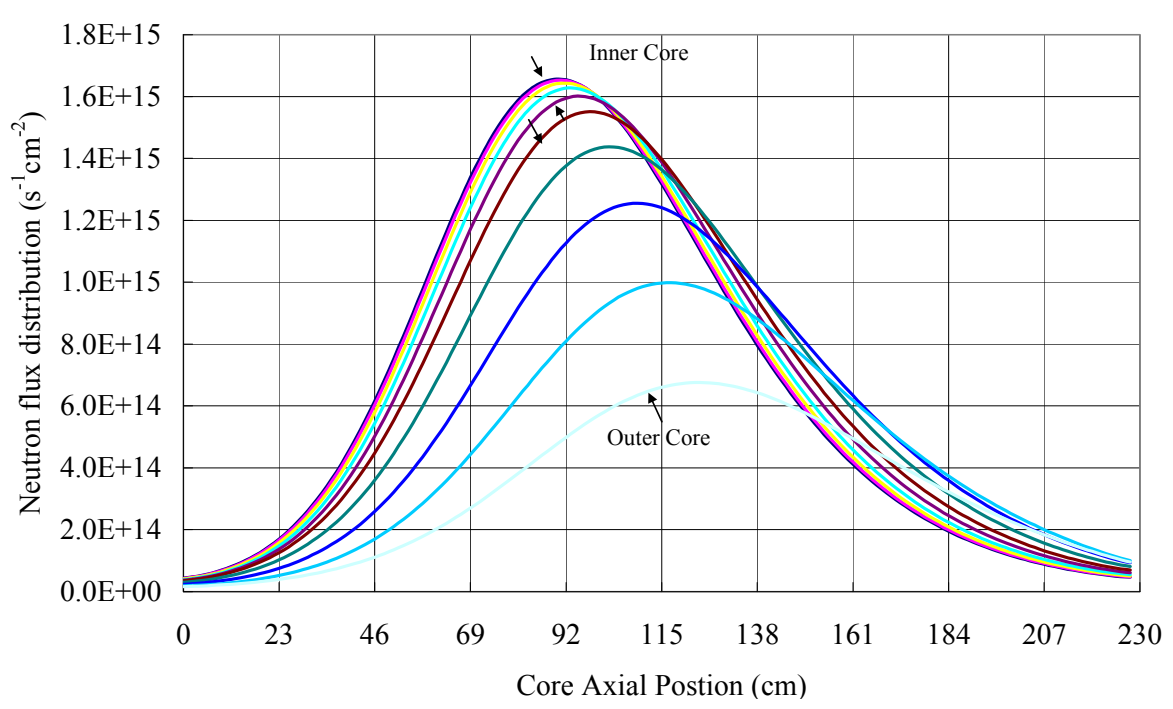


Figure 6. The thermal power distribution.

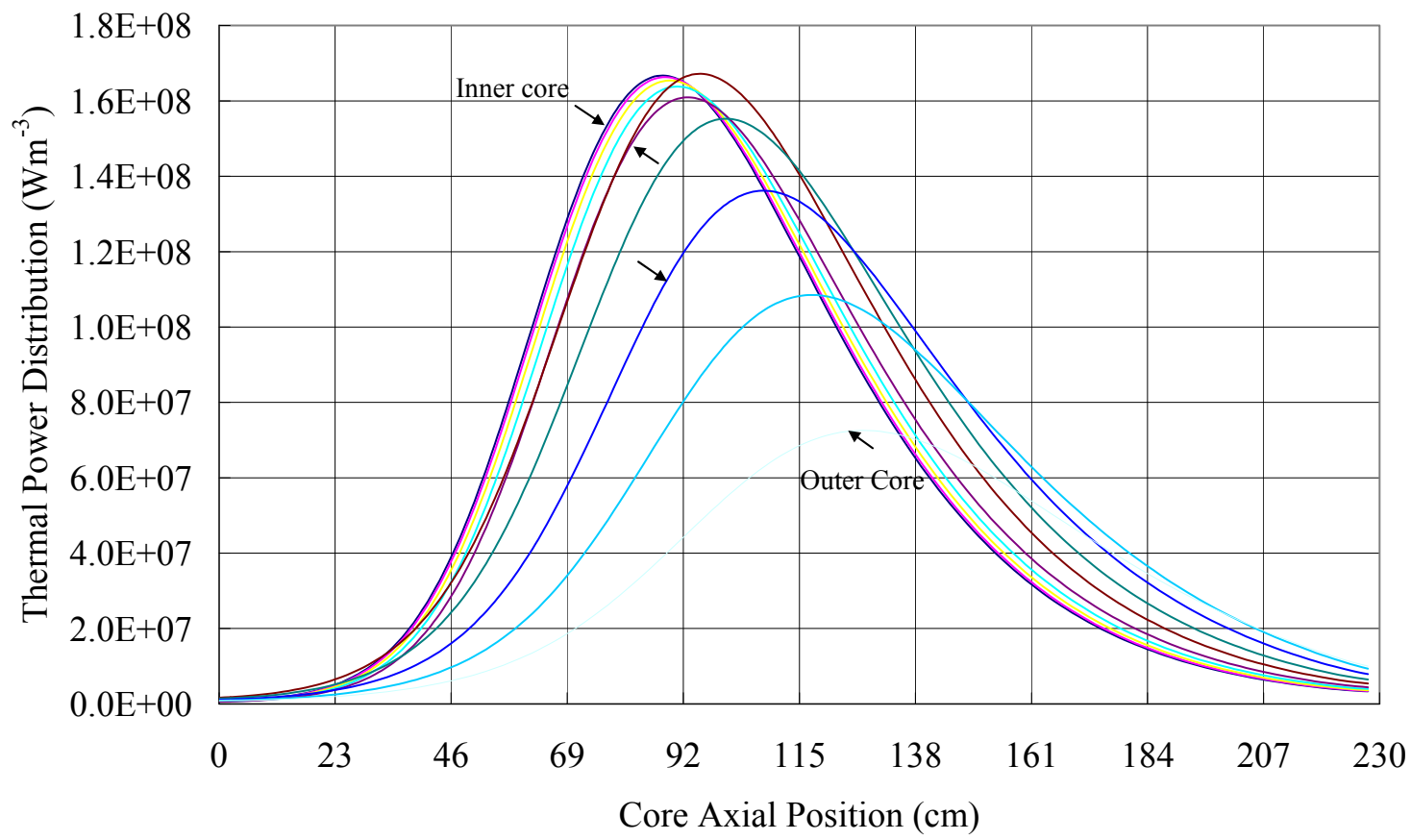

Figure 7. (a) The 3D radial neutron flux distribution at axial layer 30; (b) layer 47; (c) layer 70 and (d) layer 90 .

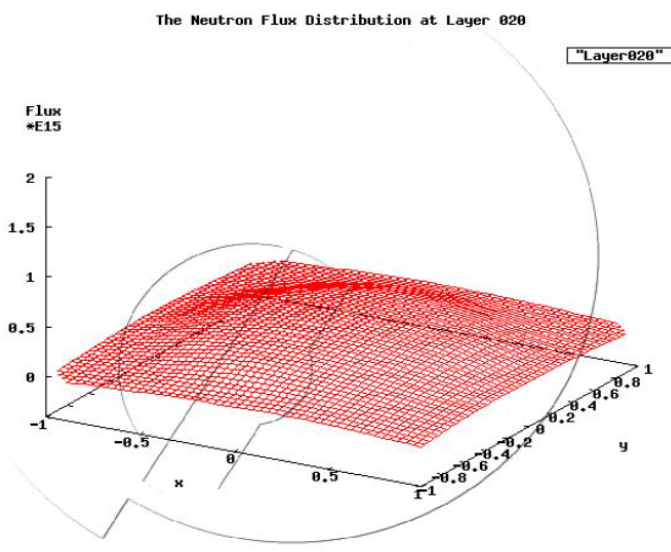

a

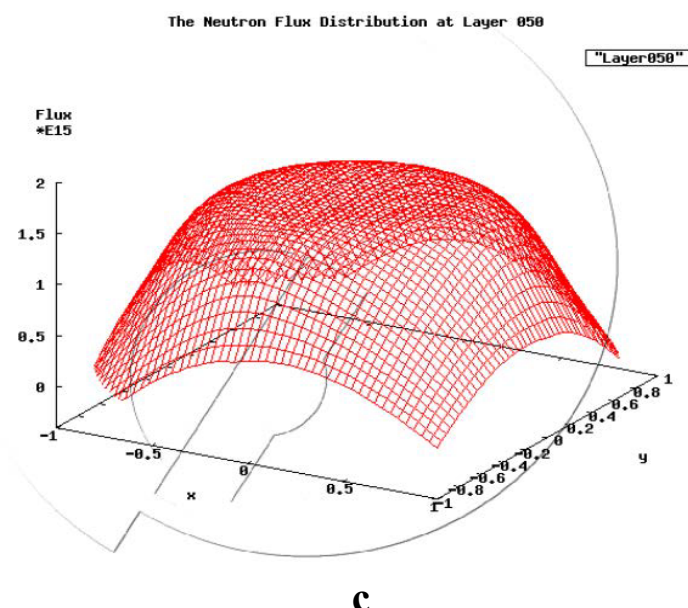

The Neutron Flux Distribution at Layer 830 "Layer838" —

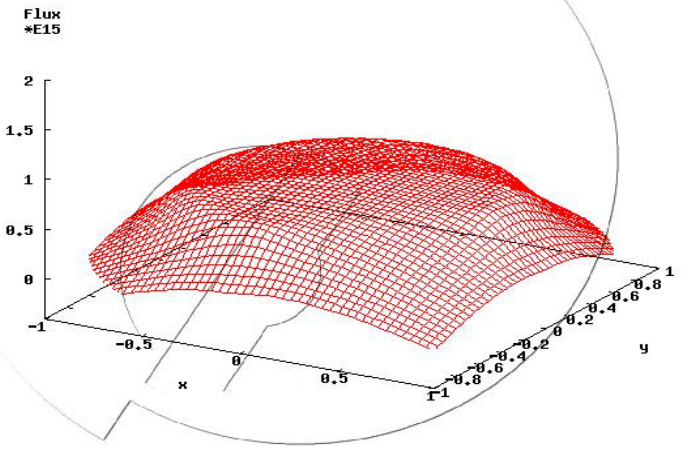

b The Neutron Flux Distribution at Layer 880

"Layer880" -

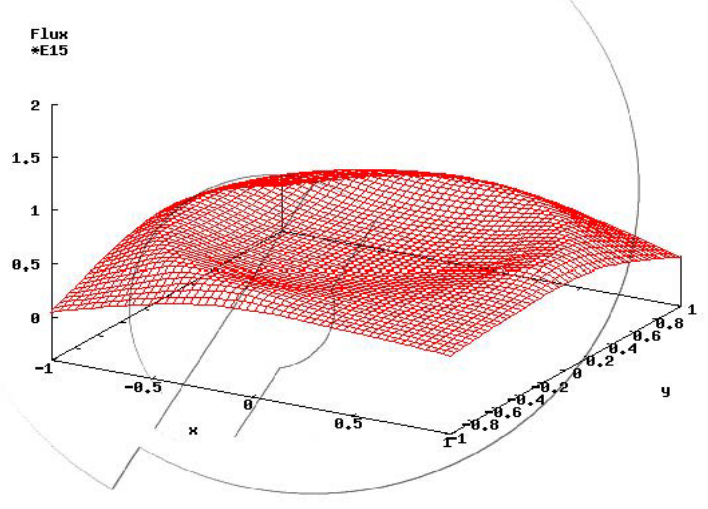

d 
With the flat radial neutron flux distribution, the temperature peaks are efficiently cut off, leaving large margin limits, as shown in Figure 8. The average coolant outlet temperature of the core is almost $773 \mathrm{~K}$ and can provide high energy efficiency. The absolute values and the discrepancies of the three temperatures are relatively small, taking advantage of the optimal characteristics of the LBE coolant and nitride fuel. Both are good heat conductors and the gap between the fuel pellets and cladding is filled with the LBE bond to enhance heat transfer. Since the pressure losses, such as the portion induced by the wrap wire of the fuel pin, are not incorporated in the calculation, the partially estimated friction pressure loss is about $0.4 \mathrm{MPa}$. To be more precise, the total core pressure loss will be presented by the CFX calculation based on our specific fuel assembly design.

Figure 8. The temperature distribution of the hottest fuel pin and coolant channel.

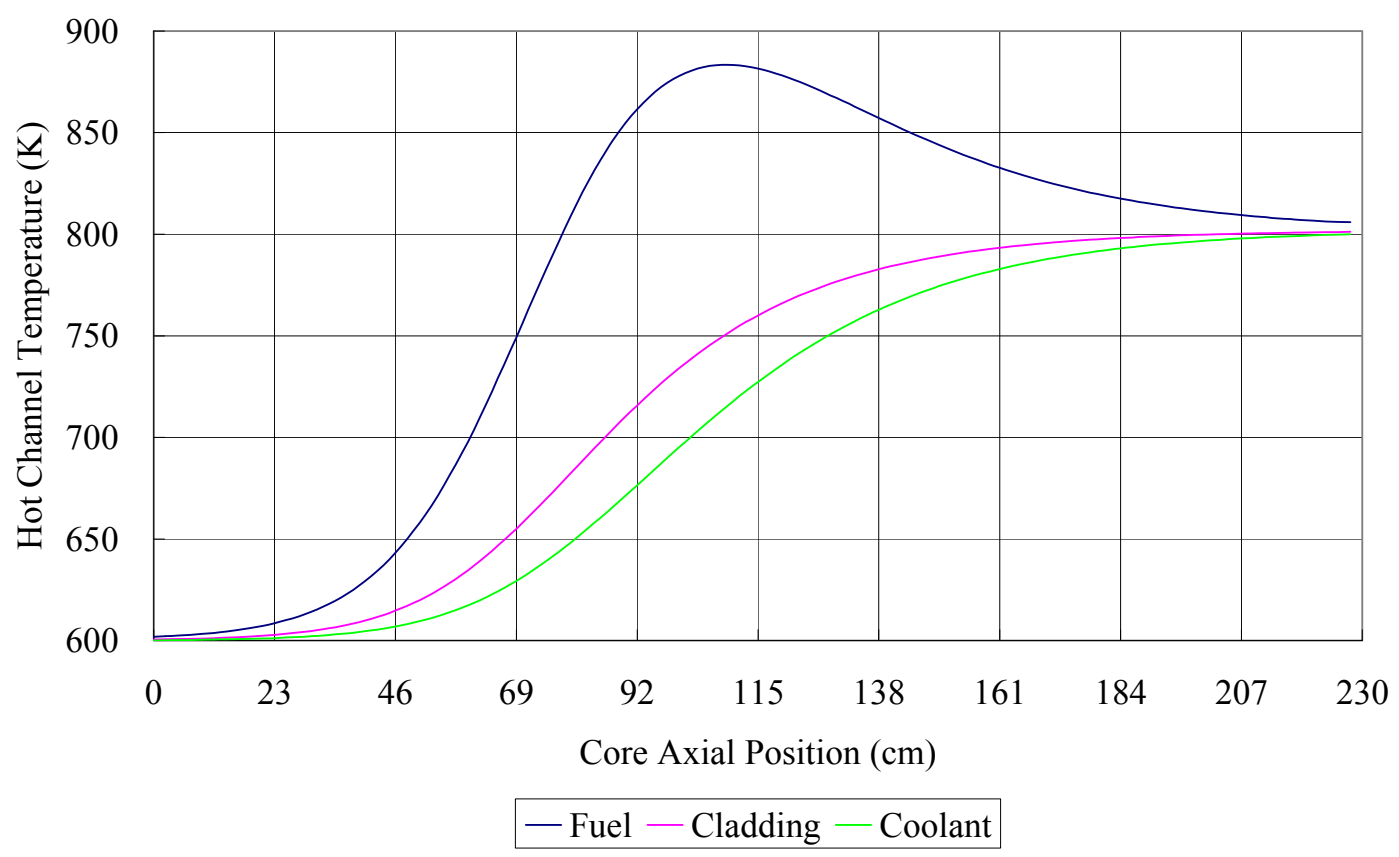

\subsection{The Design and Results of the 2000 MWth CANDLE Reactor}

In this design, we adopted a uranium-plutonium and thorium-uranium combined fuel cycle, using the th2cm6fp50bp16F burnup chain. Different from the $1000 \mathrm{MWth}$ design, the inner region is composed of the fuel assemblies containing thorium, while the outer region is filled with the uranium fuel assembly at an enrichment of $2.4 \%$. The outer region is surrounded by a $50 \mathrm{~cm}$ thick LBE reflector, as shown in Figure 9. The total empty space volume ratio in the inner region is about 5.5\%, which is available for the shutdown control rod channels and experiment/detection equipment channels. The detailed design parameters of this core are shown in Table 3.

The CANDLE reactors with a power level higher than 2000 MWth are suitable for most crowded places in the world, satisfying the rapid increase of energy demands. Such reactors could become the main supplier in the nuclear energy industry as a substitute for the present thermal reactors and fast reactors to extend the utilization of fission energy for thousands of years and, in the long run, protect the global environment. For different power level designs, we adopted the uniform geometry and configuration for the fuel pins and assemblies, considering the engineering standardization. 
Similar thermal-hydraulic designs have also been adopted to reduce difficulties and expenses in the system and variability in the conditions. The thorium fuel used in the inner region suppresses the peak of the radial neutron flux distribution and helps maintaining resource diversity. The LBE coolant is also adopted.

The key results for this case are shown in Table 4.

Figure 9. Sketch of the 2000 MWth CANDLE core configuration.
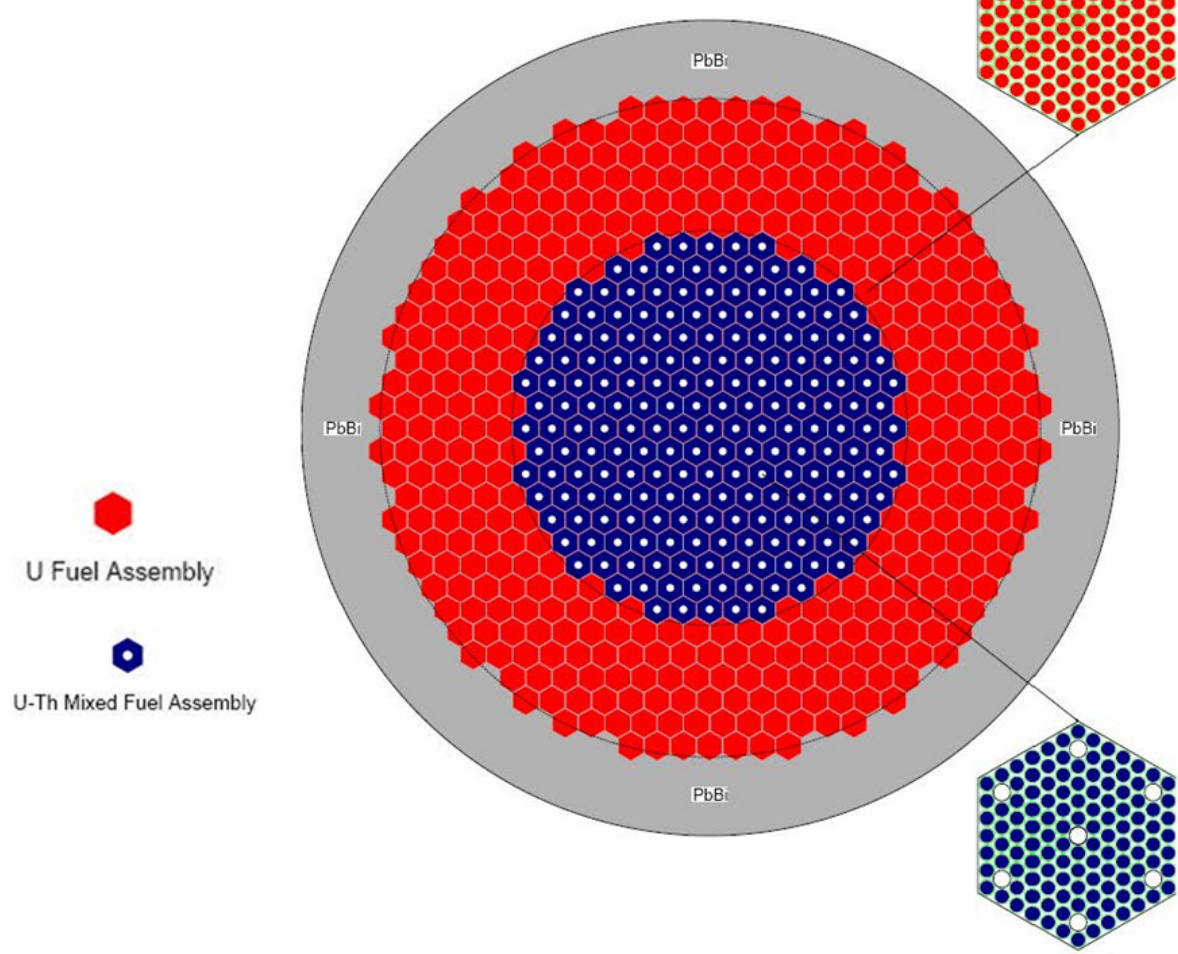

Table 3. The 2000 MWth CANDLE core design parameters.

\begin{tabular}{cc}
\hline Main Design Parameters & Values/Specifications \\
\hline Thermal Power/MWth & 2000 \\
Core Height/cm & 230 \\
Core Radius/cm & 210 \\
Radius of Inner Core/cm & 126 \\
Thickness of Reflector/cm & 50 \\
Fuel Cell Radius/mm & 6 \\
Thickness of Cladding/mm & 0.5 \\
Distance between fuel pins/mm & 0.8 \\
Fuel Material of Inner Core & Natural $82 \% \mathrm{UN} 、 18 \% \mathrm{ThN}$ \\
Fuel Material of Outer Core & Enrichment $2.4 \% \mathrm{UN}$ \\
Cladding Material & $\mathrm{HT}-9$ \\
Coolant Material & PbBi $(44.5 \%-55.5 \%)$ \\
Reflector Material & PbBi $(44.5 \%-55.5 \%)$ \\
Core Inlet Temp/K & 600 \\
Core Outlet Temp Peak/K & 800 \\
\hline
\end{tabular}


Table 4. The key results of the 2000 MWth CANDLE reactor design.

\begin{tabular}{cc}
\hline Key Results & Values \\
\hline Keff & 1.0019 \\
Burnup velocity (cm/year) & 1.84 \\
Maximum discharged fuel burn-up (\%) & 57.0 \\
Fuel temperature peak (K) & 916.7 \\
Cladding temperature peak $(\mathrm{K})$ & 801.1 \\
Maximum Coolant Velocity/m/s & 3.1 \\
\hline
\end{tabular}

When the contents of Tables 2 and 4 are compared, no qualitative difference can be found. The 2000 MWth reactor is also an extremely long life nuclear battery and needs no burnup control, nor refueling. The higher power results in faster fuel consumption, resulting in a slightly larger burnup velocity. Also, the higher power level makes the core slightly hotter. All of the parameters listed in Table 4 are well within the design limits, except for the burnup depth. As mentioned in the former section, before a more appropriate material is found, we have to face this challenge using optimized designs and measures, such as the present "recladding procedure". The question as to how to solve this challenge more satisfactorily remains an important research objective.

From Figures 10 to Figure 12, the equilibrium number density distributions of the nuclide U238, Th232, Pu239 and U233 are presented. The number density of the nuclides in the inner region is also volume weighted, in accordance with the empty space volume ratio.

Figure 10. The equilibrium nuclide number density distributions of U238 and Th232.

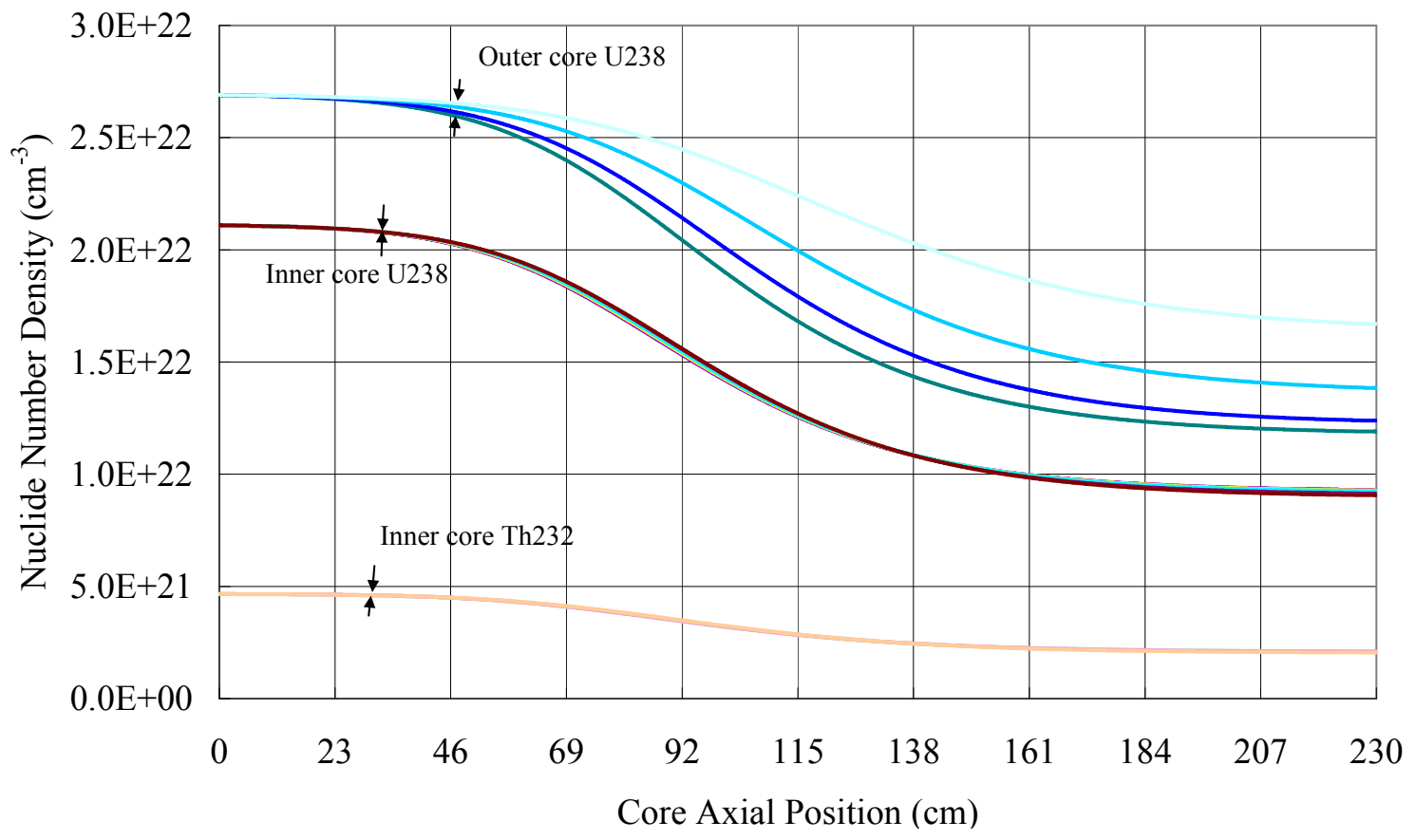


Figure 11. The equilibrium nuclide number density distribution of Pu239.

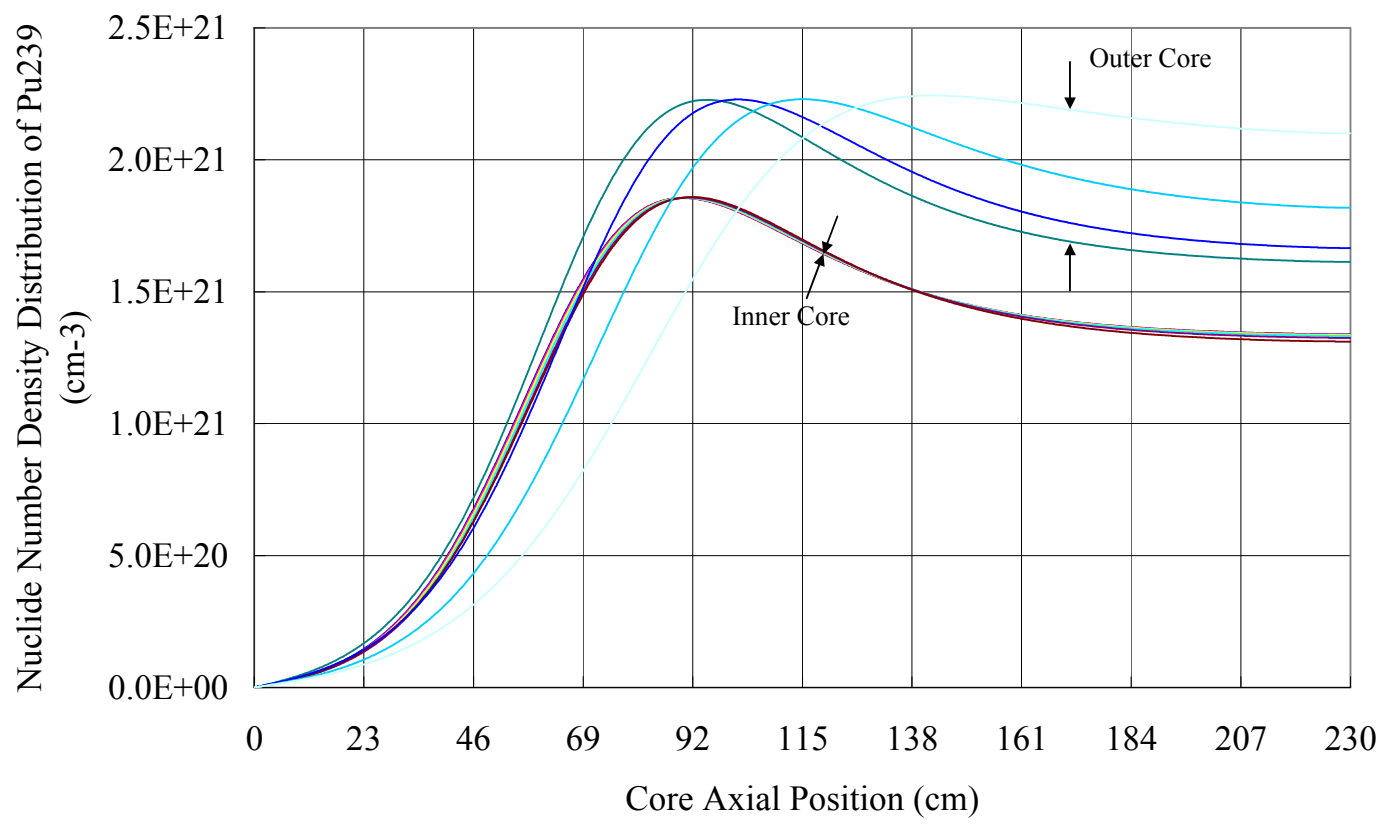

Figure 12. The equilibrium nuclide number density distribution of U233 in the inner core.

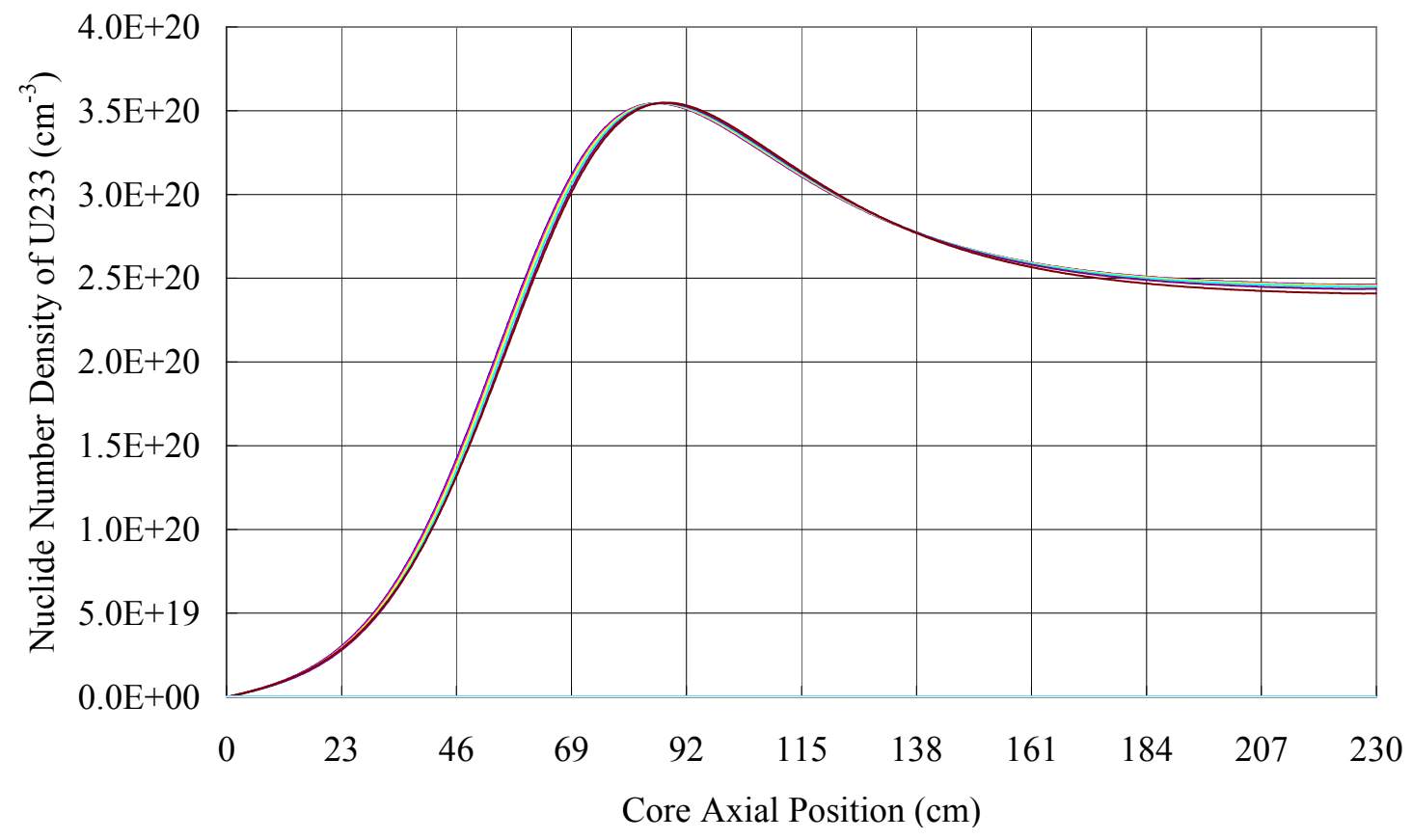

The spent fuel region is generated when the burning wave moves away and the process is extremely slow. In a rather long residence time in the core, a large amount of fast neutrons from the burning region keep bombarding the heavy nuclides in the spent fuel region, such as the minor actinides, resulting in a high transmutation ratio of the CANDLE core, as shown in Table 5. 
Table 5. The number densities of the main MAs and the plutonium isotopes in the spent fuel region of outer core.

\begin{tabular}{cccc}
\hline Nuclide & Number Density $\left(\mathbf{c m}^{-\mathbf{3}}\right)$ & Nuclide & Number Density $\left(\mathbf{c m}^{\mathbf{3}}\right)$ \\
\hline Np236 & $1.21 \mathrm{e} 15$ & Am241 & $1.05 \mathrm{e} 20$ \\
Np237 & $3.52 \mathrm{e} 19$ & Am242M & $5.62 \mathrm{e} 18$ \\
Pu236 & $4.46 \mathrm{e} 13$ & Am243 & $8.38 \mathrm{e} 18$ \\
Pu238 & $4.59 \mathrm{e} 19$ & $\mathrm{Cm} 242$ & $1.14 \mathrm{e} 17$ \\
Pu239 & $1.61 \mathrm{e} 21$ & $\mathrm{Cm} 243$ & $3.33 \mathrm{e} 16$ \\
Pu240 & $7.76 \mathrm{e} 20$ & $\mathrm{Cm} 244$ & $1.73 \mathrm{e} 18$ \\
Pu241 & $3.33 \mathrm{e} 19$ & $\mathrm{Cm} 245$ & $4.56 \mathrm{e} 17$ \\
Pu242 & $4.12 \mathrm{e} 19$ & $\mathrm{Cm} 246$ & $1.41 \mathrm{e} 17$ \\
\hline
\end{tabular}

The summed up number density of $\mathrm{Np}$, Am and $\mathrm{Cm}$, including all their isotopes counted in the calculation, is about $1.57 \mathrm{e} 20 \mathrm{~cm}^{-3}$, which is only $0.57 \%$ of that of the uranium isotopes in the fresh fuel. For a fast reactor, the corresponding ratio would be many times higher. Compared with the LWR, the spent fuel amount per produced heat energy is only $10 \%$ of LWR in the once-through cycle, according to the burnup depth. Also, if the thermal efficiency is taken into account, the ratio would be reduced to $7 \%$ or even less. The CANDLE reactor is suitable for adopting the once-through cycle, considerably reducing the indirect waste generated by the reprocessing, which can usually be thousands of times the amount of the spent fuel. The conclusion should be drawn that the CANDLE reactor is an incredible converter, burner, transmutator and environment saver all in one.

Figure 13 shows the infinite neutron multiplication factor distribution. In the inner region, the U233 transmuted from Th232 decides the distribution of the factor. In the outer region, the dominator is the Pu239 transmuted from U238.

Figure 13. The infinite neutron multiplication factor distribution.

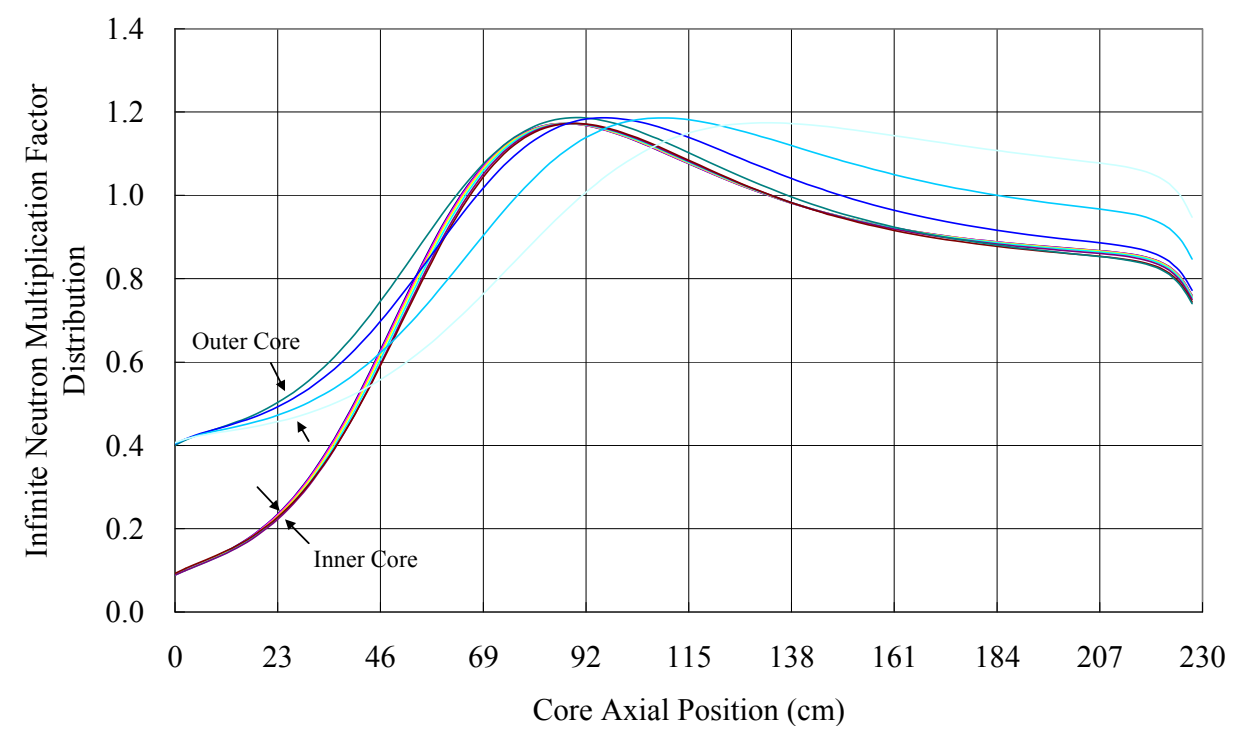

Figures 14 and 15 show that on every axial layer of the burning region, more than $50 \%$ of the area is covered by the same neutron flux and power level. More than $80 \%$ of the area is covered by the neutron flux, i.e. between $1.9 \mathrm{e} 15 \mathrm{~cm}^{-2} \mathrm{~s}^{-1}$ to $1.0 \mathrm{e} 15 \mathrm{~cm}^{-2} \mathrm{~s}^{-1}$ at the axial flux peak. Compared with the 1000 MWth case, a much flatter flux distribution covers a larger area, as shown in the 3D figures of 
Figure 16. Because the core radius is increased, the neutron loss from the inner core region introduced by radial leakage is weakened. This reminds us that a more functional reflector would enhance the flattening of the radial flux distribution. According to Figure 17, the burning region that is exposed to the highest radiation would take about 16.2 years to reach the damage neutron fluence limit, which is about $250 \mathrm{dpa}\left(5.0 \mathrm{e} 23 \mathrm{~cm}^{-2}\right)$ from the fresh state (the counted neutrons have an energy level higher than $0.1 \mathrm{MeV}$, which is about $50 \%$ of the summation for the present case). This time limit is restricted by the maximum local radiation dose along the fuel assembly with maximum power output and the proportion of the high energy neutrons. So the radial neutron flux distribution is required to be as flat as possible to extend the time limit.

Figure 14. The neutron flux distribution.

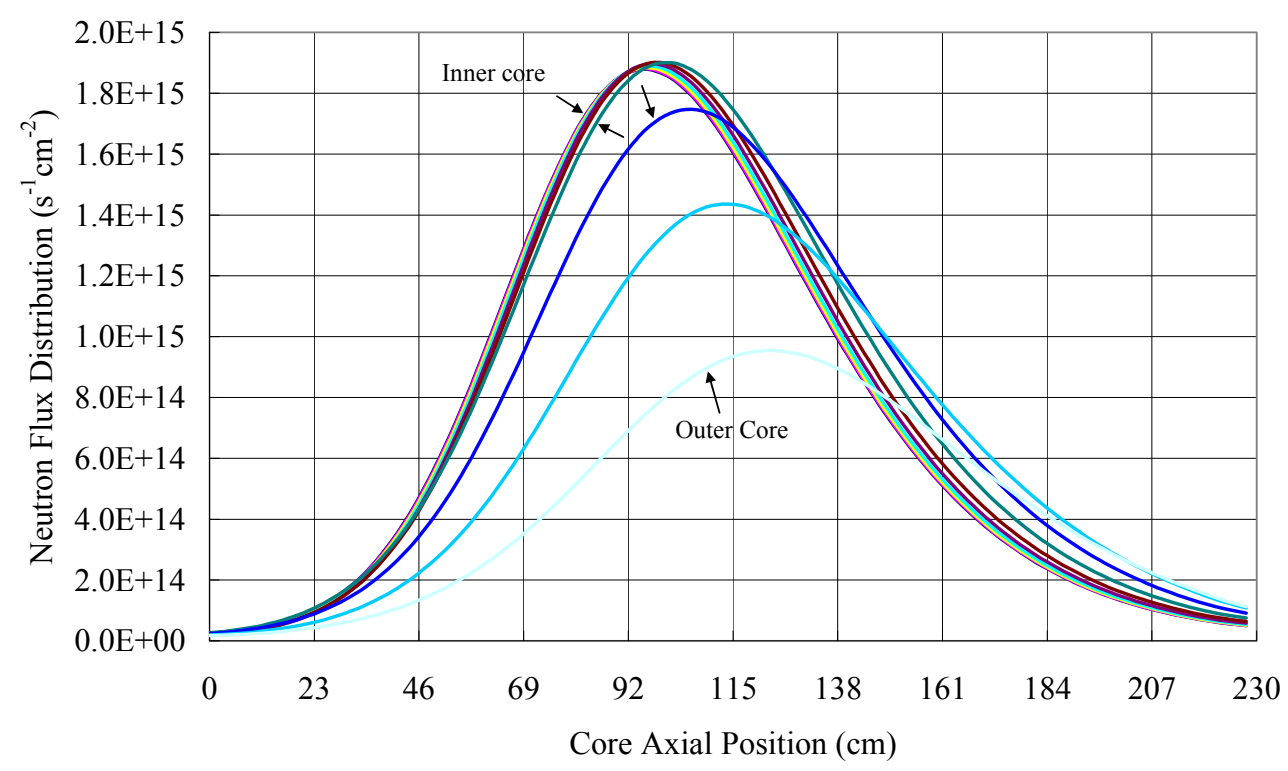

Figure 15. The thermal power distribution.

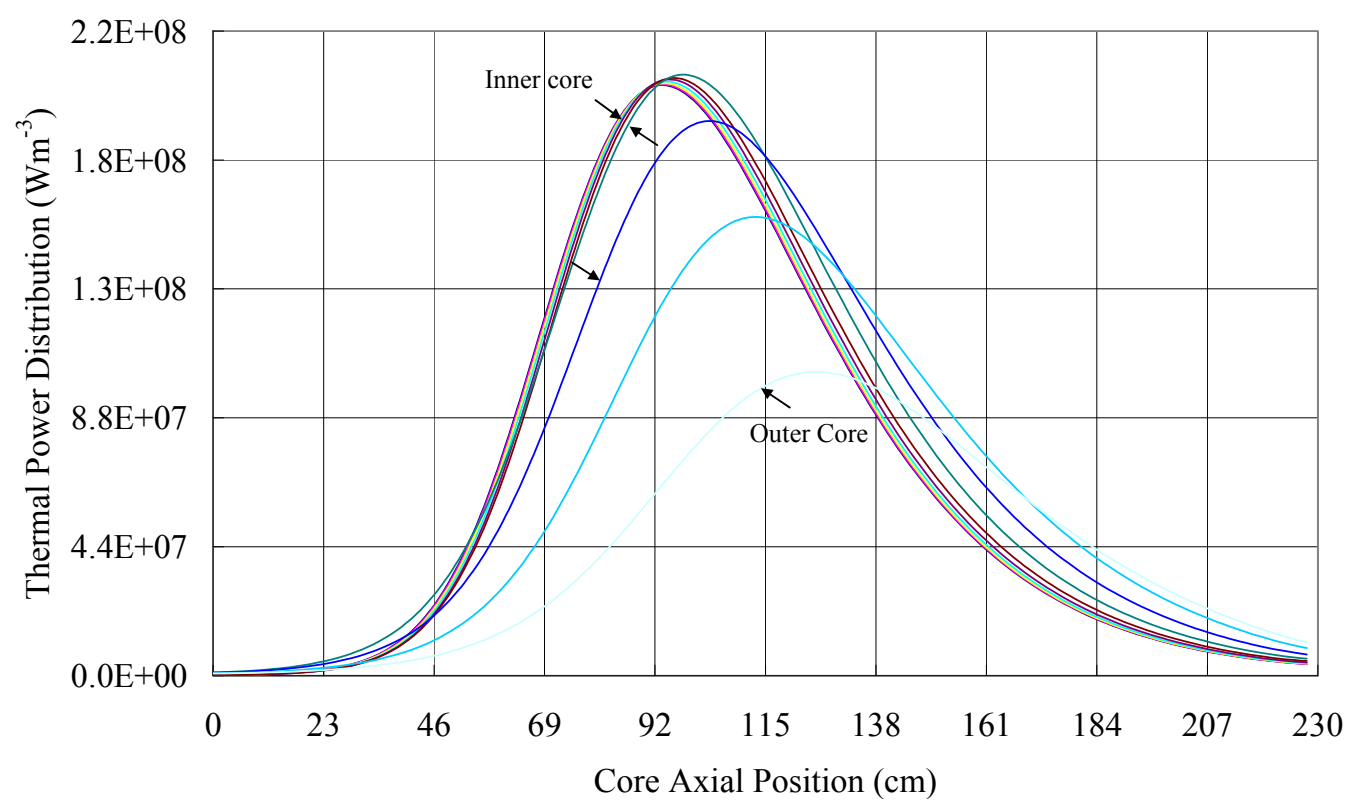


Figure 16. (a) The 3D radial neutron flux distribution at axial layer 30; (b) layer 40; (c) layer 60 and (d) layer 80 .
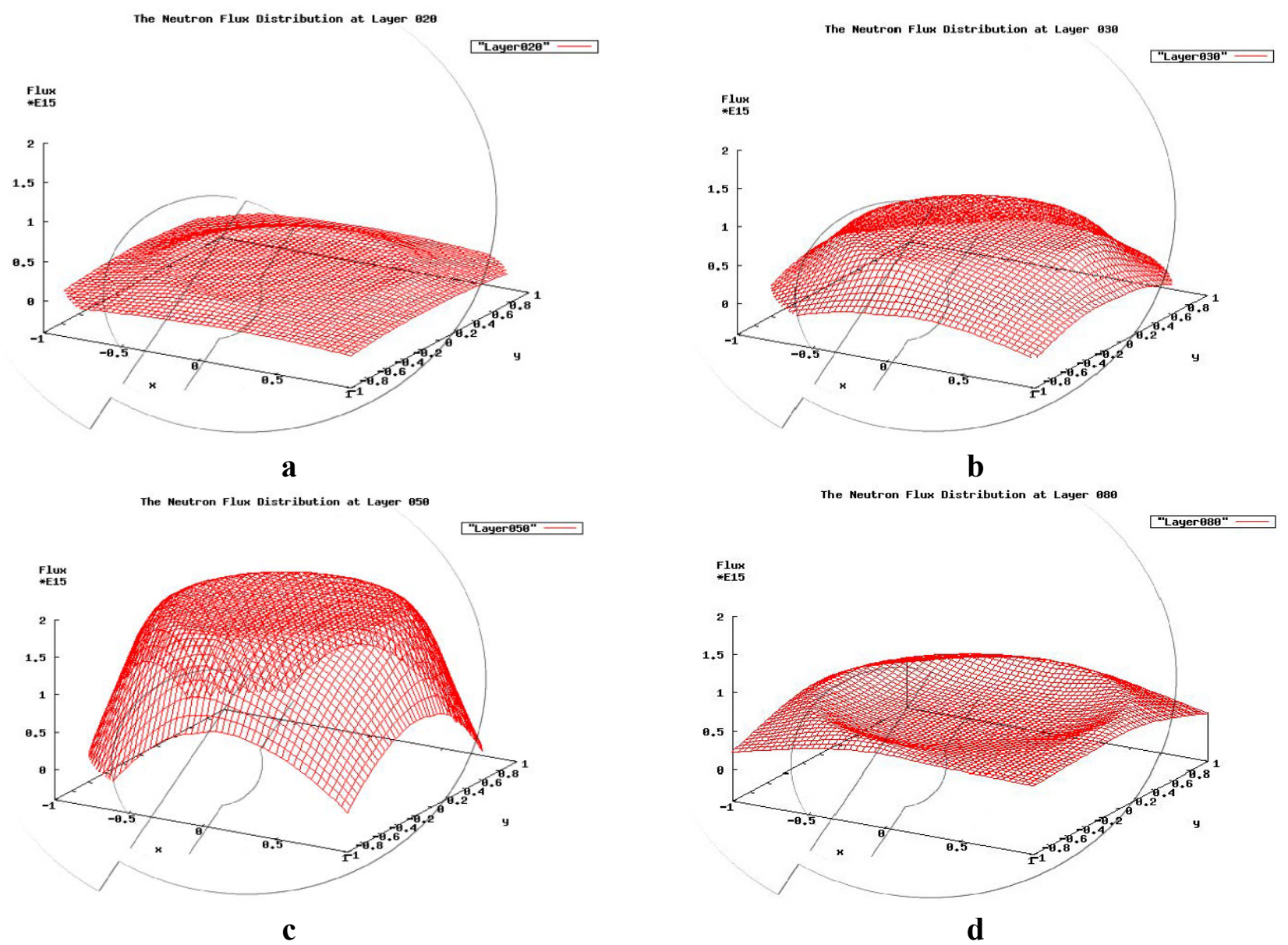

A CANDLE reactor core, which can operate continuously for approximately 16 years with full 2000 MWth power output, is very impressive, compared with any other fission reactors and is the obvious evolution of nuclear fission energy utilization of the human society. Another key point is that this CANDLE reactor can be realized based on currently existing technologies and materials. Furthermore, the operation capability of the CANDLE reactor will improve along with the advancements in key elements, especially the cladding material.

If we set the core life to 60 years, the burning wave will travel about $110 \mathrm{~cm}$ in the core axial direction, according to the burnup velocity, and the maximum neutron fluence damage a fuel assembly could get is about $1.29 \mathrm{e} 24 \mathrm{~cm}^{-2}$. Seventy percent of the core will get the fluence beyond $1.0 \mathrm{e} 24 \mathrm{~cm}^{-2}$ and it will take about 37 years for the most radiated fuel assembly to reach this value. If a cladding material supports the $500 \mathrm{dpa}\left(1.0 \mathrm{e} 24 \mathrm{~cm}^{-2}\right)$ without any devastating integrity crisis, then $30 \%$ of the core $(174 \mathrm{~cm} \sim 210 \mathrm{~cm}$ in the radial direction) does not need any treatment for the whole life of the core. After 37 years of full power operation without a break, recladding or just simply refueling will be needed for the first and only time in the 60 year lifespan of the core. Additionally, if a suitable material is found to survive the $645 \mathrm{dpa}$, then the whole core would realize full power operation without a break for 60 years.

The rough estimation above only considers the effect of "dpa". For the real situation, the aging, erosion and other effects should be seriously considered too. However, these effects will not obstruct 
the capability and the potential of the CANDLE reactor to make nuclear fission energy utilization as simple and clean as possible.

The recladding procedure is a complicated operation involving radioactive hot cells and the technology needed is not yet ready for a large scale engineering application. It should be noted, however, that recladding is a feasible technique, which may well be much easier and cheaper than reprocessing. The following two engineering approaches could be considered as alternatives to the development of recladding technology:

- Firstly, following the CANDLE advancements, a simple refueling mode without any recladding procedure being necessary could be realized. Refueling would be carried out every 15 years conservatively, taking $250 \mathrm{dpa}$ as the limit margin. Thus, in the 60 years core life, the CANDLE will require a very low-level enriched fuel inventory for four cores and will need to be shut down four times in total. At the same time, research and radiation testing of cladding materials should be pushed forward. With the development of suitable materials, the refueling amount and frequency could be reduced and might well be eventually eliminated. A fast reactor with the same power level usually needs refueling every 1.5 years, i.e., in an assumed 60 year core life, it needs a fuel inventory for 13 cores, which is much higher enriched, and shutting down a total of 40 times. It becomes apparent that the CANDLE reactors are the rational substitute for fast reactors.

- Continue with the SWR (Standing Wave Reactor) development proposed by TerraPower LLC [11-13]. Theoretically, a SWR does not need refueling or recladding, but has a complicated shuffling operation of the fuel assemblies every $2 \sim 3$ years. Also, the development of cladding materials is also critical for this reactor, because better material could reduce the frequency of the shuffling operations and the amount of the fuel assemblies involved. A SWR does not automatically maintain the steady burnup or maintain the flattened radial flux distribution. Also, the frequent shuffling of the irradiated fuel assemblies poses engineering challenges. On another aspect, the burnup ratio of a SWR is lower than that of a CANDLE, introducing lower irradiation damage to the materials and lower utilization capability of nuclear resources at the same time. We could presume that the SWR is a compromise for the CANDLE for easier engineering approaches and as a support of the CANDLE in the development process for better materials.

Figure 17 shows the temperatures of the hottest fuel pin and the corresponding coolant temperature distribution along the core axis. We can conclude that the core operates with large safety margins. The partially estimated friction pressure loss is less than $0.9 \mathrm{MPa}$ and usually a large pressure loss of the primary loop could be predicted for a forced LBE cooled reactor with large power output. 
Figure 17. The temperature distribution of the hottest fuel pin and coolant channel.

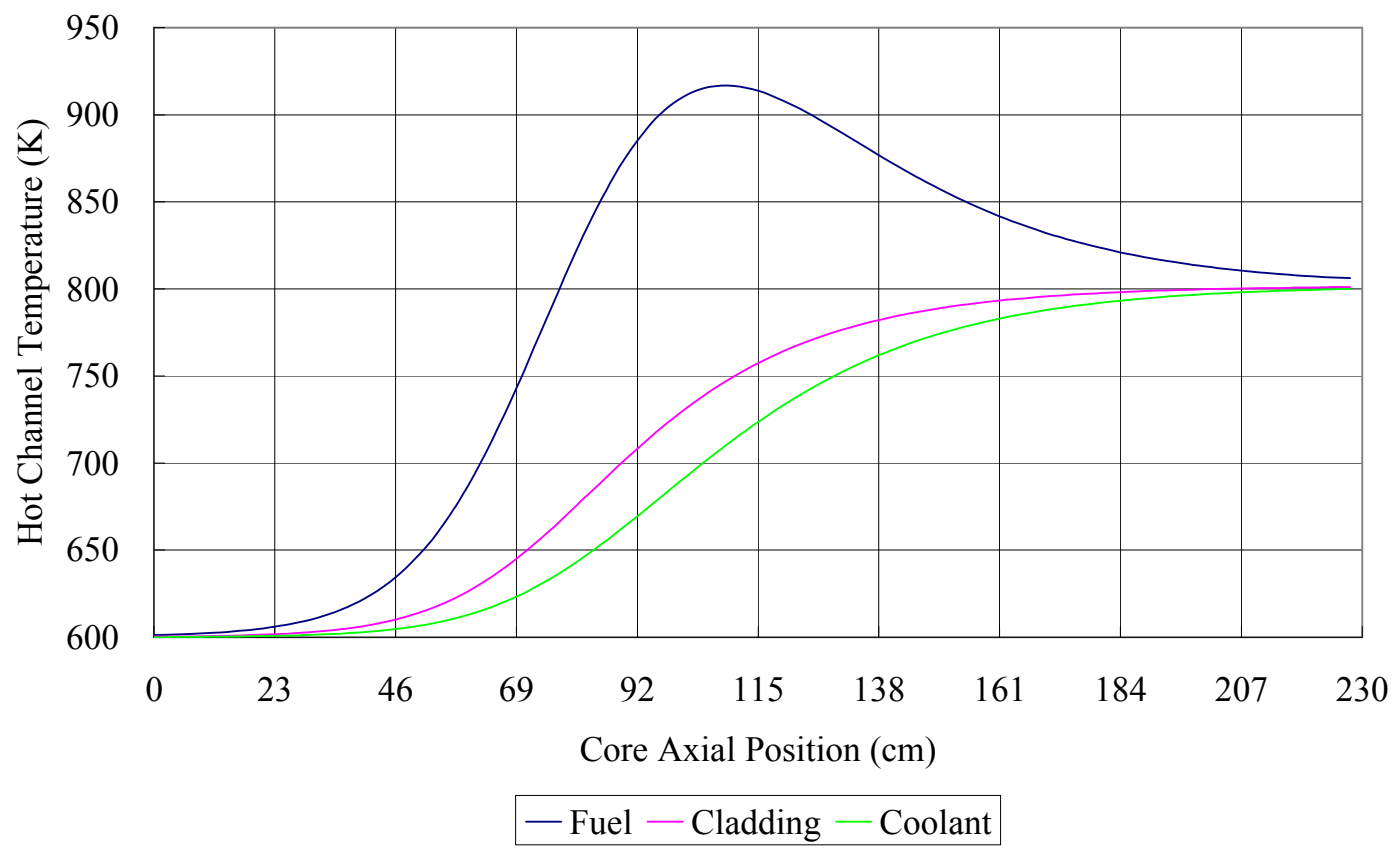

\section{Conclusions}

Both the 1000 MWth and the 2000 MWth CANDLE reactor designs presented in this paper successfully flattened the radial neutron flux distributions by different configurations and fuel compositions. This reflects the inherent characteristics of the CANDLE burnup, and the flexible and strong chassis provided that allows the designers to achieve various features. The design features could be kept for the life of the core, instead of being changed along the burnup process, as is necessary in other fission reactors. "CANDLE" is not just a new concept, but a novel way of how a reactor can burn, with new attributes that would be shared by a new type of nuclear system.

Based on the current materials and technologies, achieving four continuous 15 year operation periods with full power over the 60 year core life is a reasonable engineering goal, with the potential of extending the operation period further until eliminating shutting down due to the material limits. The recladding procedure and the simple refueling procedure are options to match the CANDLE road map in the early stage, and the later one might be more feasible for easier engineering. The SWR is also attractive, though it faces the same kind of challenges brought about by the high burnup. Both are excellent substitutes for fast reactors, combining the conversion, burnup and transmutation in one place simultaneously, greatly improving the utilization of nuclear fission energy and removing the heavy burden brought about by reprocessing, without even a mention of the special merits presented by the core performance.

Further research and development will focus on the fuels, materials and the various reactor designs needed to satisfy the engineering demands.

\section{Conflict of Interest}

The authors declare no conflict of interest. 


\section{References}

1. Sekimoto, H.; Ryu, K.; Yoshimura, Y. CANDLE: The new burnup strategy. Nucl. Sci. Eng. 2001, 139, 306-317.

2. Yan, M.Y.; Sekimoto, H. Design research of small long life CANDLE fast reactor. Ann. Nucl. Energy 2008, 35, 18-36.

3. Sekimoto, H.; Udagawa, Y. Effects of fuel and coolant temperatures and neutron fluence on CANDLE burnup calculation. J. Nucl. Sci. Technol. 2006, 43, 189-197.

4. Sekimoto, H.; Zaki, S. Design study of lead- and lead-bismuthcooled small long-life nuclear power reactors using metallic and nitride fuel. Nucl. Technol. 1994, 109, 307-313.

5. Yan, M.Y.; Sekimoto, H. Safety analysis of small long life CANDLE fast reactor. Ann. Nucl. Energy 2008, 35, 813-828.

6. Nagata, A.; Takaki, N.; Sekimoto, H. A feasible core design of lead bismuth eutectic cooled CANDLE fast reactor. Ann. Nucl. Energy 2009, 36, 562-566.

7. Deng, L.; Xie, Z.; Zhang, J. MCMG: A 3-D multigroup $\mathrm{P}_{3}$ monte carlo code and its benchmarks. J. Nucl. Sci. Technol. 2000, 37, 608-614.

8. Okumura, K.; Kugo, T.; Kaneko, K.; Tsuchihashi, K. SRAC2006: A comprehensive neutronic calculation code system, JAEA-Data/Code 2007-004; Report; Japan Atomic Energy Agency: Ibaraki, Japan, 2007.

9. Waltar, A.E.; Reynolds, A.B. Fast Breeder Reactors; Pergamon Press: New York, NY, USA, 1981.

10. Nagata, A.; Sekimoto, H. Effects of Recladding in CANDLE Reactor; ANS/ENS International Meeting, Washington, DC, USA, 11-15 November 2007.

11. Ellis, T.; Petroski, R.; Hejzlar, P.; Zimmerman, G.; McAlees, D.; Whitmer, C.; Touran, N.; Hejzlar, J.; Weaver, K.; Walter, J.C.; et al. Traveling-Wave Reactors: A Truly Sustainable and Full-Scale Resource for Global Energy Needs. In Proceedings of 2010 International Congress on Advances in Nuclear Power Plants, Nice, France, 13-17 June 2010; p. 10189.

12. Weaver, K.; Ahlfeld, C.; Gilleland, J.; Whitmer, C.; Zimmerman, G. Extending the Nuclear Fuel Cycle with Traveling-Wave Reactors. In Proceedings of Global 2009, Paris, France, 6-11 September 2009; p. 9294.

13. Weaver, K.D.; Gilleland, J.; Ahlfeld, C.; Whitmer, C.; Zimmerman, G. A Once-Through Fuel Cycle for Fast Reactors. In Proceedings of the 17th International Conference on Nuclear Engineering, Brussels, Belgium, 12-16 July 2009; pp. 845-851.

(C) 2012 by the authors; licensee MDPI, Basel, Switzerland. This article is an open access article distributed under the terms and conditions of the Creative Commons Attribution license (http://creativecommons.org/licenses/by/3.0/). 